Journal of Bangladesh Academy of Sciences, Vol. 37, No. 1, 1-10, 2013

\title{
ADSORPTION MECHANISM OF 2, 4-DICHLOROPHENOL ON FERRIC OXIDE FROM AQUEOUS SOLUTION
}

\author{
T. S. A. ISLAM, H. A. BEGUM, M. A. HOSSAIN*AND M. MONIRUZZAMAN \\ Department of Chemistry, University of Dhaka, Dhaka-1000, Bangladesh
}

\begin{abstract}
The adsorption of 2, 4-dichlorophenol (2, 4-DCP) from aqueous solution on ferric oxide was carried out in a batch process. The experiments were done to determine the equilibrium time of adsorption, effect of temperature, $\mathrm{pH}$, electrolytes and substituted groups of adsorbate to elucidate the mechanism of the adsorption. The estimated equilibrium time was found to be three hours. The adsorption was found to increase with increasing temperature from $30-50^{\circ} \mathrm{C}$. The numerical values of differential heat of adsorption increased with increasing surface coverage suggesting that the adsorption on ferric oxide might be chemical in nature. The adsorption of 2, 4-DCP on ferric oxide was found to increase with increasing $\mathrm{pH}$ of the solution from 3.0 - 5.0 but further increase of solution $\mathrm{pH}$ from 5.0 - 8.0 decreased the adsorption. Electrolytic effect showed that the adsorption was favorable in presence of $\mathrm{NO}_{3}{ }^{-}$ion as compared with $\mathrm{Cl}^{-}$ion. The effect of substituted groups showed that the amount of 2, 4-DCP adsorbed on ferric oxide was lower than that of 2, 5-DCP. Such observations suggest that the adsorption of 2, 4-DCP on $\mathrm{Fe}_{2} \mathrm{O}_{3}$ is dominated by the electrostatic force of attraction between DPC ions and iron oxide surface in aqueous media.
\end{abstract}

Key words: 2, 4-dichlorophenol, Ferric oxide, Adsorption isotherm, Temperature, pH, Electrolytes, Substituting group

\section{INTRODUCTION}

The wastes of pulp and paper industries, petrochemicals, agrochemicals, plastic industries and preservative industries are major sources of chlorinated phenols. Chlorophenols are used as pesticides, herbicides, insecticides etc. Through the discharge of these industrial wastes and through the decomposition of pesticides, herbicides, the pollutants enter into soil and aquatic environment. The chlorophenols are hazardous to aquatic lives. So it is necessary to treat effluents containing chlorophenols prior to its discharge into water. Various methods such as chemical oxidation, coagulation, chlorination, solvent extraction, liquid membrane permeation and adsorption are used for their removal (Juang et al. 1996, Ozbelge et al. 2002). Among the methods adsorption is relatively simple and inexpensive.

Many investigations were carried out regarding the removal of chlorophenols from the environment, using suitable adsorbents such as iron and aluminum oxides (King-His

*Corresponding author: <hossainabul@yahoo.com>. 
and Mebride 1991), natural soil (Lagas 1988), manganese (III or IV) oxide (Hans-Jakab and Store 1989), clay minerals (Yang 2006), oxide-coated sand (Shingh et al. 2002), kaolin and white clay (Islam et al. 1997) etc. Some of them are expensive and some are less effective depending on their sources and properties of the adsorbent. The removal of chlorophenols from wastewater by adsorption using activated carbon (Ruery-Shin and Shwu-Haw 1996) and synthetic resins (Huang and Ostovic 1989) had also been investigated. Activated carbon is an ideal adsorbent for organic matter due to its organophilic character. High cost of activated carbon has prompted to search for low cost alternatives.

Iron oxide $\left(\mathrm{Fe}_{2} \mathrm{O}_{3}\right)$ was selected as an adsorbent for the present study. Ferric oxide is also available as ore. Attempts have been made to investigate the possibilities for the removal of 2, 4-dichlorophenol (2, 4-DCP) from aqueous solution by adsorption on iron oxide as a cost effective treatment method. In the present work, the equilibrium time for adsorption, the adsorption isotherms and isobars were determined. The effects of temperature, $\mathrm{pH}$ and electrolytes on adsorption were investigated. The comparative adsorption of 2, 4-DCP and 2, 5-DCP was also investigated.

\section{MATERIALS AND METHODS}

Analytical grade 2, 4-DCP (Fluka, Japan) was used without further treatment. All solutions of 2, 4-DCP were prepared in $0.05 \mathrm{M} \mathrm{NaNO}_{3}$ (Merck Germany) solution in deionized double distilled water. In some cases $\mathrm{NaCl}$ (Merck Germany) was also used to maintain the ionic strength of 2, 4-DCP solution instead of $\mathrm{NaNO}_{3}$. The ferric oxide powder of $\mathrm{BDH}$ (England) was used as an adsorbent. Particle size of $\mathrm{Fe}_{2} \mathrm{O}_{3}(\mathrm{BDH})$ was 50 to $100 \mu \mathrm{m}$ in diameter. Before use, the adsorbent was oven dried at $110^{\circ} \mathrm{C}$ for 4 hours to remove any moisture content of ferric oxide surface.

An adsorption experiment was carried out in batch method using $0.2 \mathrm{~g}$ of ferric oxide and $25 \mathrm{~mL}$ of $5 \times 10^{-4} \mathrm{M} 2,4-\mathrm{DCP}$ solution at $\mathrm{pH} 5.0$ in each of a series of bottles. All bottles were shaken in a thermostated mechanical shaker at $30 \pm 1^{\circ} \mathrm{C}$. After different time of intervals each bottle was withdrawn and the supernatants were transferred and centrifuged repeatedly until clear solutions were obtained. The $\mathrm{pH}$ of clear solutions was again adjusted to $\mathrm{pH}$ 5.0. It was done in such a way that during the adjustment of $\mathrm{pH}$, addition of acid or alkali did not practically affect the total volume of adsorbate. The absorbance of the clear solution was measured by UV-visible spectrophotometrer (UV160A Spectrophotometer, Shimadzu, Japan). The experiment was continued for 5 hours. The amount adsorbed was plotted against the adsorption time as shown in Fig. 1.

To determine the adsorption isotherm of 2, 4-DCP on ferric oxide, adsorption experiments were carried out using estimated equilibrium time of 3 hours at different

initial concentrations of 2, 4-DCP ranging from $0.5 \times 10^{-4}$ to $8 \times 10^{-4} \mathrm{~mol} / \mathrm{L}$ at $\mathrm{pH} 5.0$ and 
$30^{\circ} \mathrm{C}$. To obtain the adsorption isotherms at different temperatures, the adsorption experiments were repeated at 40 and $50^{\circ} \mathrm{C}$ keeping other parameters constant. The experiment was repeated at room temperature for $\mathrm{pH} 3.0$ and 8 to study the effect of $\mathrm{pH}$ on adsorption. To determine the effect of electrolytes on the adsorption, experiments were carried out at $30^{\circ} \mathrm{C}$ with $0.05 \mathrm{M} \mathrm{NaCl}$, instead of $0.05 \mathrm{M} \mathrm{NaNO}_{3}$ at pH 5 . An adsorption experiment was also performed at $30^{\circ} \mathrm{C}$ with 2, 5-DCP in $0.05 \mathrm{M} \mathrm{NaNO}_{3}$ at pH 5.0 to compare its adsorption with 2, 4-DCP.

\section{RESULTS AND DISCUSSION}

Equilibrium time is very important for batch adsorption study. The time at which the rate of adsorption is equal to the rate of desorption i.e. the change of concentration of adsorbate in bulk solution is negligible. The equilibrium time for the adsorption of 2, 4DCP on ferric oxide has been estimated from the plot of amount adsorbed vs contact time in Fig. 1. It was found that after three hours of contact time no significant change of 2, 4DCP concentration occurred in solution for continuing the process. Therefore, three hours was considered as the equilibrium time for this adsorption system.

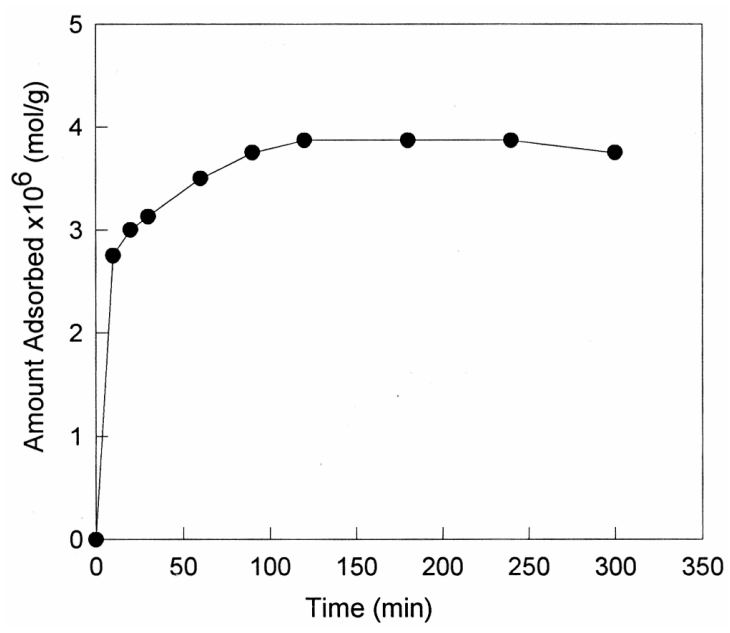

Fig. 1. Variation of amount adsorbed with contact time for the adsorption of 2, 4-DCP on ferric oxide at $\mathrm{pH} 5.0$ and $30^{\circ} \mathrm{C}$.

Effects of temperature: The adsorption isotherms of 2, 4-DCP on ferric oxide at different temperatures are shown in Fig. 2. The isotherms were of sigmoid nature showing no saturation limits suggesting that the adsorption does not follow either Langmuir or Freundlich equations. Similar observations were made during the adsorption study of 2, 4-DCP on kaolin and white clay (Islam et al. 1997) in solution at pH 3.0 and adsorption of 2, 4-DCP on alumina at $\mathrm{pH} 2.6$ (Hossain et al. 1999). 
The adsorption isobar for a definite equilibrium concentration of $7.0 \times 10^{-5} \mathrm{M}$ of 2 , 4-DCP is shown in Fig. 3. It shows that the amount adsorbed increased with the rise of temperature. Such an observation indicates that the adsorption might be chemisorption. The adsorption of 2, 4-DCP on metal oxides was observed to be both physisorption and chemisorption depending on the experimental conditions and the type of oxides. Adsorption of 2, 4-DCP on kaolinite (Islam et al. 1997) and 2, 5- DCP on ferric oxide (Tareq 2006) was chemisorption but adsorption of 2, 4-DCP on alumina (Hossain et al. 1999) surface was physisorption.

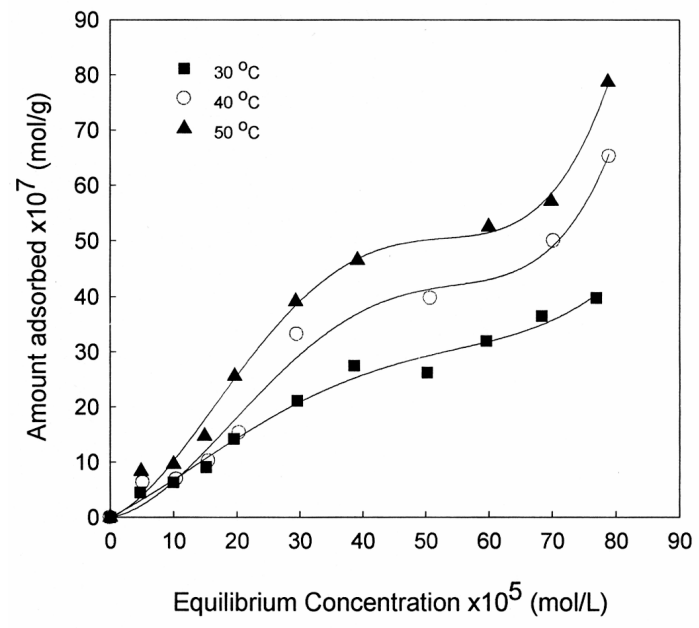

Fig. 2. Adsorption isotherms of 2, 4-DCP on ferric oxide for different temperatures.

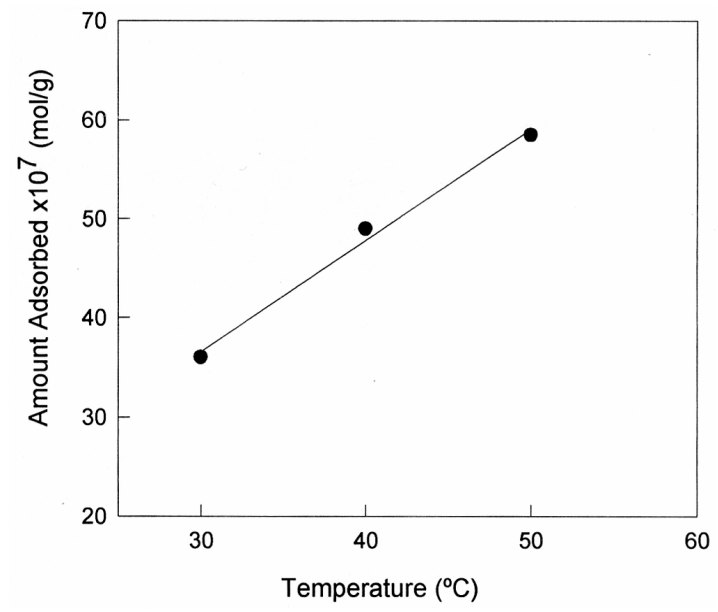

Fig. 3. Adsorption isobar of 2, 4-DCP on ferric oxide for equilibrium concentration of $7 \times 10^{-5} \mathrm{~mol} / \mathrm{L}$ at $\mathrm{pH} 5.0$. 
Heat of adsorption: The differential heat of adsorption $\left(\Delta H_{\mathrm{ads}}\right)$ for different surface coverage has been obtained for $\mathrm{pH} 5$ from the slope of linear plot of $-\ln C_{\mathrm{e}}$ vs $1 / T$ shown in Fig. 4. It shows that with the increase of surface coverage, the numerical values of $\Delta H_{\text {ads }}$ increases from $14.3-35.6 \mathrm{~kJ} / \mathrm{mol}$. As the surface coverage increases, probabilities of the collisions between adsorbate-adsorbed molecules and within the adsorbed molecules might be increased. So the adsorption at higher surface coverage needs more energy of activation. This might be the reason for the increasing heat of adsorption with the increasing surface coverage. The positive heat of adsorption indicates that the adsorption process is endothermic. The endothermicity proves the heterogeneous character of ferric oxide surface. The low values of heat of adsorption indicate weak interactions of adsorbate molecules with the surface. The negative heat of adsorption was observed during the adsorption of 2, 4-DCP on alumina (Hossain et al. 1999) and $\mathrm{MnO}_{2}$ (Rafia 1998) suggesting that the adsorption was due to the physical force of attraction.

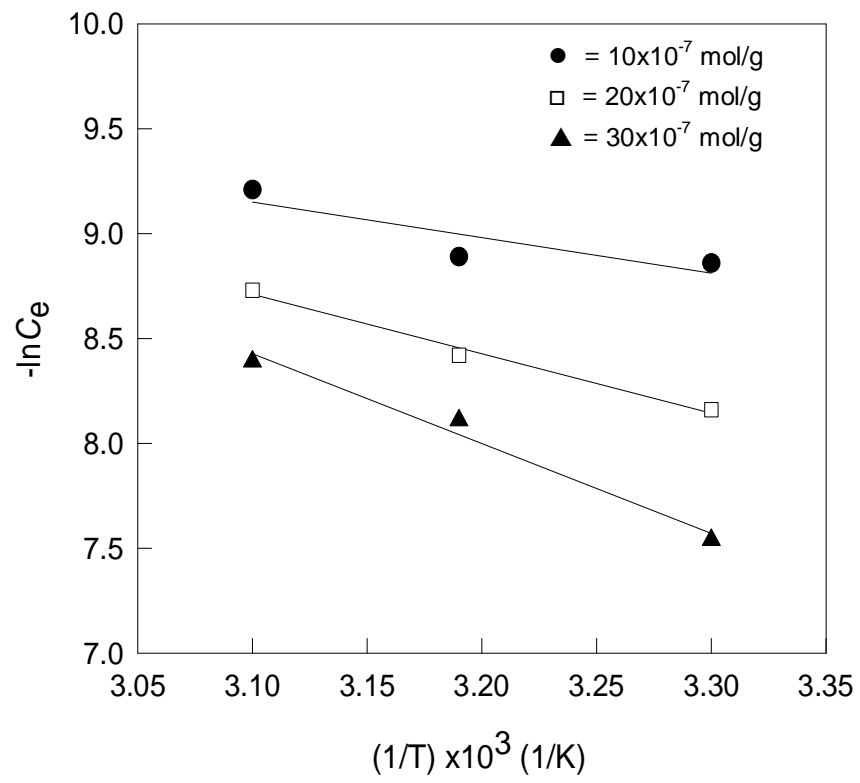

Fig. 4. Plot of $-\ln C_{\mathrm{e}}$ vs $1 / T$ for different values of surface coverage at $\mathrm{pH} 5.0$.

$\mathrm{pH}$ of solution plays a significant role in case of adsorption of solid-liquid interface. The surface of ferric oxide and the chemical properties of 2, 4-DCP are influenced by the $\mathrm{pH}$ of the medium. To study the effect of $\mathrm{pH}$ on adsorption, adsorption isotherms were constructed at different $\mathrm{pH}$ values of solutions as shown in Fig. 5. For a fixed equilibrium concentration, the amount adsorbed at different $\mathrm{pH}$ obtained from Fig. 5, have been plotted in Fig. 6 to identify the effect of $\mathrm{pH}$ on adsorption. The adsorption of 2, 4-DCP on 
ferric oxide surface is not favoured either by highly alkaline or acidic medium. In dilute solution of 2, 4-DCP, the following equilibrium exists :<smiles>[O-]c1ccc(Cl)cc1Cl</smiles>

Equilibrium existence of 2, 4-DCP in aqueous medium

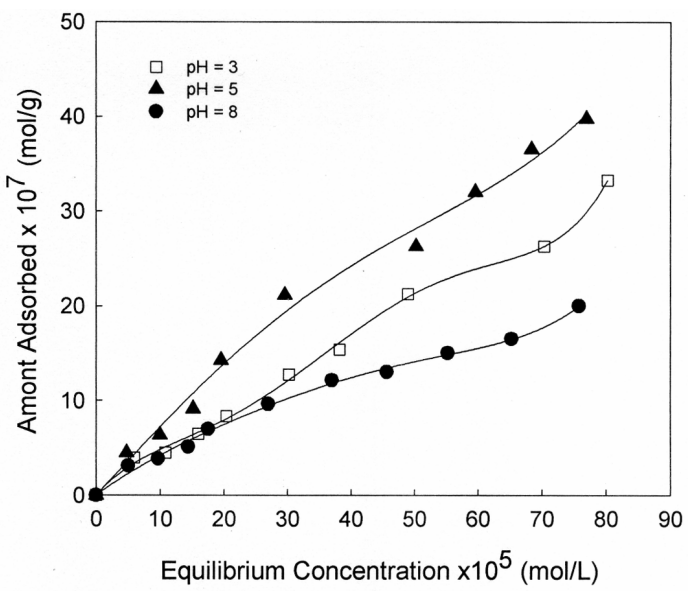

Fig. 5. Adsorption isotherm of 2, 4-DCP on ferric oxide at different $\mathrm{pH}$ values of solutions.

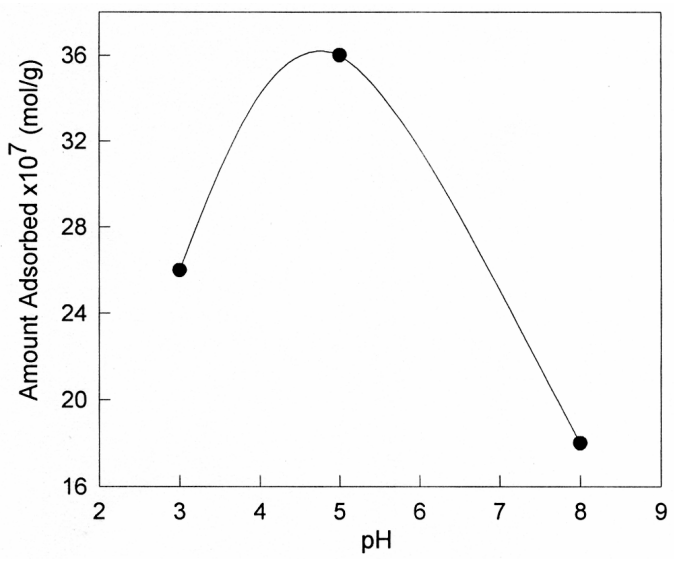

Fig. 6. Variation of amount adsorbed with initial pH.

When the $\mathrm{pH}$ of the solution is 5.0, the proportion of the phenolate ion is more than that of phenol. Since the $\mathrm{pH}_{\mathrm{zpc}}$ of ferric oxide is close to 8.0, at $\mathrm{pH}$ lower than 8.0, surface 
becomes positively charged. Thus the interaction between the positively charged adsorbent and negatively charged phenolate ion becomes greater.

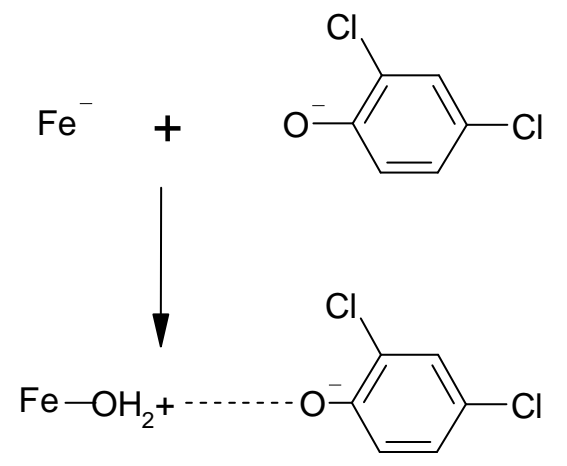

When the $\mathrm{pH}$ of the solution is decreased from 5.0 to 3.0, the adsorption decreased. At lower $\mathrm{pH}$, amount of undissociated phenol increases. The interaction of phenol with the positively charged adsorbent is weaker than the phenolate ion and this lowers the adsorption.

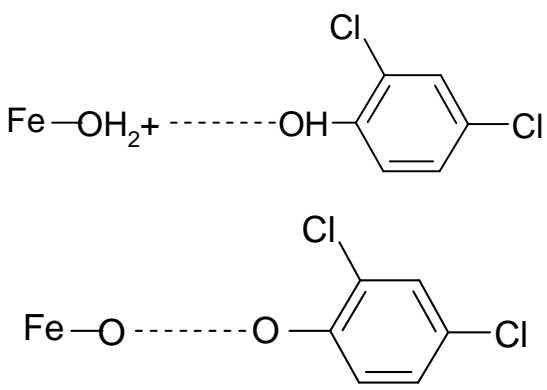

At pH 8.0, the surface of iron oxide was slightly negative and DCP molecules mostly remained as anion. The interaction between the negatively charged phenolate ion and negatively charged surface is unlikely. So the adsorption is much lower than acidic medium. Similar observations had been obtained during the adsorption study of 2, 4-DCP on kaoline (Islam et al. 1997) and alumina (Hossain et al. 1999) surface and 2, 5-DCP on ferric oxide (Tareq 2006) surface.

The effect of electrolytes on adsorption has been studied at $30^{\circ} \mathrm{C}$ using the solution pH 5.0 to investigate the effect of electrolytes on the process. Fig. 7 shows that the amount of adsorption decreases when $\mathrm{NO}_{3}^{-}$ions are replaced by $\mathrm{Cl}^{-}$ions. This might be due to the fact that the accumulation of $\mathrm{Cl}^{-}$ions at the positively charged (at $\mathrm{pH}$ 5) interface hinders the approach of phenolate anions towards interface. Since $\mathrm{NO}_{3}{ }^{-}$ions are less electronegative than $\mathrm{Cl}^{-}$ions, they do not have significant effect on the accumulation of phenolate ions on the interface. 


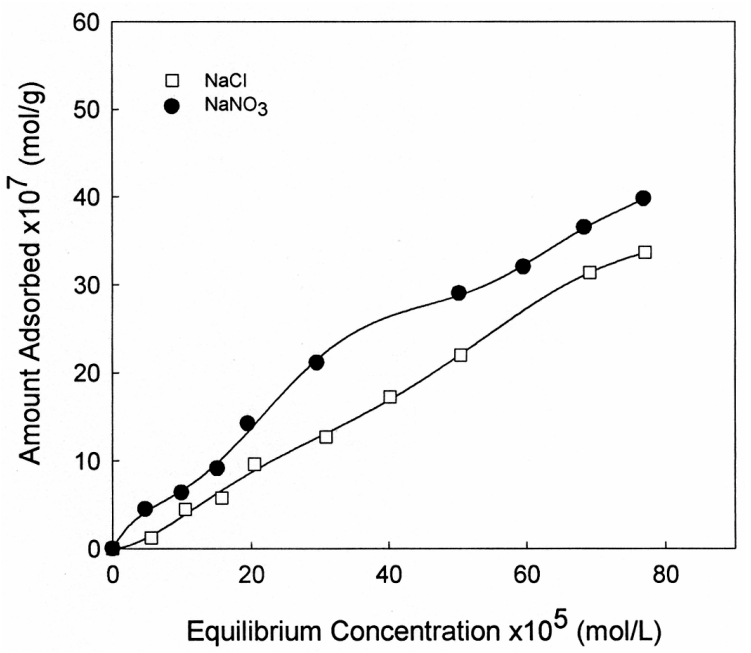

Fig. 7. Adsorption isotherms of 2, 4-DCP on ferric oxide in presence of $\mathrm{Cl}^{-}$and $\mathrm{NO}_{3}{ }^{-}$ions at $\mathrm{pH}$ 5.0.

The position of substituents plays an important role in the adsorption of dichlorophenol on ferric oxide. Fig. 8 compares the adsorption isotherms of 2, 4-DCP and 2, 5DCP on ferric oxide surface at $\mathrm{pH}$ 5.0. Amount of 2, 5-DCP adsorbed on ferric oxide surface was higher than that of 2, 4-DCP under same experimental conditions. Literature survey shows that the dissociation constant of 2, 5-DCP $\left(\mathrm{K}_{\mathrm{a}}=4.47 \times 10^{-8}\right)$ in aqueous solution is higher than that of 2, 4-DCP $\left(\mathrm{K}_{\mathrm{a}}=4.26 \times 10^{-8}\right)$ (Ezerskis and Jusys 2001). Since more phenolate ions were available for 2, 5-DCP than 2, 4-DCP at pH 5, higher adsorption was observed in case of 2, 5-DCP.

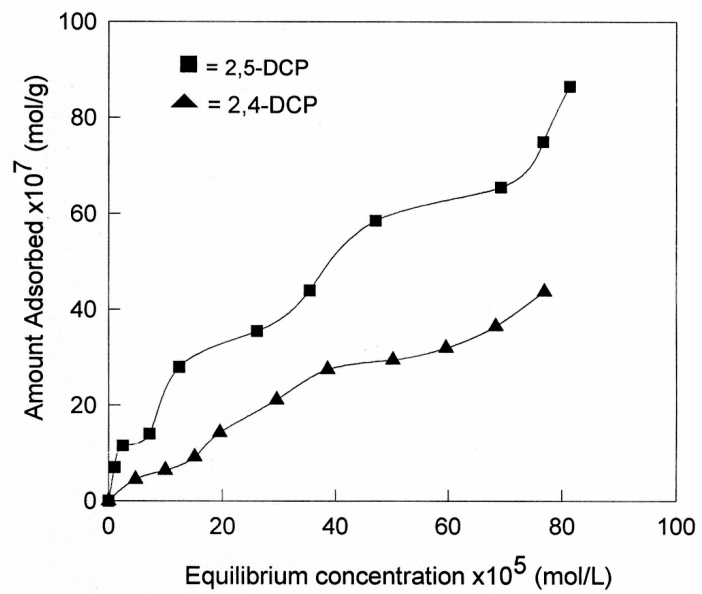

Fig. 8. Adsorption isotherms of 2, 5-DCP and 2, 4-DCP on ferric oxide surface at $\mathrm{pH} 5.0$. 


\section{CONCLUSIONS}

The adsorption of 2, 4-DCP on ferric oxide at $\mathrm{pH} 5.0$ showed that the amount adsorbed increased with the increase of temperature suggesting chemisorptions. This may be due to the co-ordination of 2, 4-DCP with ferric oxide surface. The numerical values of heat of adsorption increased with an increase of surface coverage suggesting activated adsorption.

$\mathrm{pH}$ of the solution affects the adsorption of 2, 4-DCP on ferric oxide. Adsorption at $\mathrm{pH} 3.0$ is low which is due to the interactions between protonated $\mathrm{Fe}-\mathrm{OH}_{2}{ }^{+}$groups of ferric oxide surface and 2, 4-DCP molecules. At pH 5.0 the adsorption is increased due to the interactions between 2, 4-dichlorophenolate anions and $\mathrm{Fe}_{-} \mathrm{OH}_{2}{ }^{+}$group on ferric oxide surface. At $\mathrm{pH} 8.0$ the rapid fall of adsorption may be due to the interaction between the negatively charged phenolate ion and negatively charged surface $\left(\mathrm{FeO}^{-}\right)$.

Electrolytes significantly affect the adsorption. The amount adsorbed decreases when $\mathrm{NO}_{3}{ }^{-}$ions are replaced by $\mathrm{Cl}^{-}$ions. Since $\mathrm{Cl}^{-}$ions are more electronegative than $\mathrm{NO}_{3}{ }^{-}$ions, chloride ions accumulate on the positively charged interface and due to the repulsive effect the accumulation of phenolate anions on the interface decreased significantly.

\section{ACKNOWLEDGEMENTS}

The authors gratefully acknowledge the Chairperson, Department of Chemistry, University of Dhaka, Bangladesh for providing facilities during the study.

\section{REFERENCES}

Ezerskis, Z. and Z. Jusys. 2001. Oxidation of chlorophenols on Pt electrode in alkaline solution studied by cyclic voltammetry, galvanostatic electrolysis and gas chromatograph-mass spectroscopy (GC-MS). Pure Appl. Chem. 73(12): 1929-1940.

Hans-Jakab, U. and A.T. Store. 1989. Oxidation of chlorophenols adsorbed to manganese oxide surfaces. Environ. Sci. Technol. 23(4): 421-427.

Hossain, A.K.M.Z., M.A. Hossain, F. Khanom, H.A. Begum, M.Q. Ehasan and T.S.A. Islam. 1999. Adsorption behaviour of dichlorophenol on alumina. Dhaka Univ. J. Sci. 47(2): 167-175.

Huang, C.P. and F.B. Ostovic. 1989. Removal of organic compounds by activated carbon adsorption. J. Env. Div. ASCE 104: 863-869.

Islam, T.S.A., M.Q. Ehsan, H.A. Begum and F. Khanom. 1997. Adsorption of 2, 4DCP on kaolinite. J. Bangladesh Chem. Soc. 10(1): 51-58.

Juang, R.S., F.C. Wu and R.L. Tseng. 1996. Adsorption isotherms of phenolic compounds from aqueous solutions onto activated carbon fibers. J. Chem. Eng. Data 41: 487-492.

King-His, K. and M.B. Mebride. 1991. Bonding of chlorophenols on iron and aluminun oxides. Environ. Sci. Technol. 25(4): 701-709.

Lagas, P. 1988. Adsorption of chlorophenols on soils. Chemosphere 17(2): 205-216.

Ozbelge, T.A., H.O. Ozbelge and S.Z. Baskaya. 2002. Removal of phenolic compounds from rubber-textile wastewaters by physicochemical methods. Chem. Eng. and Process 41: 719730. 
Rafia, I. 1998. Adsorption of 2, 4-DCP on Manganese (IV) Oxide - Aqueous Interface. M.Sc. Thesis, Department of Chemistry, Dhaka University.

Ruery-Shin and L. Shwu-Haw. 1996. Liquid-phase adsorption of phenol and its derivatives on activated carbon fibers. Sep. Sci. Technol. 31(4): 1915-1921.

Shingh, D.K., B. Srivvastva and P. Yadav. 2002. Iron oxide coated sand as a adsorbent for separation and removal of phenols. Indian J. Chem. Technol. 9: 285-289.

Tareq, S.M. 2006. Adsorption behaviour of 2, 5-DCP onto ferric oxide solution interface. M.S. Thesis, Department of Chemistry, Dhaka University.

Yang, H. 2006. Exchange of reactions of phenilic pollutants on clay surfaces. Haiyang Zue Bao (Zhongwenban) 14(5): 135-141.

(Received revised manuscript on 22 January, 2013) 